ORIGINAL RESEARCH ARTICLE

\title{
TELFest: an approach to encouraging the adoption of educational technologies
}

\author{
Farzana Latif* \\ University of Sheffield, Sheffield, UK \\ (Received 16 May 2016; final version received 11 December 2016)
}

\begin{abstract}
Barriers to technology adoption in teaching and learning are well documented, with a corresponding body of research focused on how these can be addressed. As a way to combine a variety of these adoption strategies, the University of Sheffield developed a Technology Enhanced Learning Festival, TELFest. This annual, week-long event, emphasises the role technology can play through an engaging learning experience which combines expert-led practical workshops, sharing of practice, discussions and presentations by practitioners. As the popularity of the event has grown and the range of topics expanded, a community of practice has organically coalesced among attendees, supporting the mainstream adoption of several technologies and helping to broaden educational innovation beyond isolated pockets. This paper situates TELFest within the technology adoption literature by providing details about TELFest, outlining the results of an investigation into the impact that it has had on attendees' teaching practice and summarising some of the limitations of the method along with reflections on how to address these limitations in the future.
\end{abstract}

Keywords: academic adoption; barriers; challenges; technology enhanced learning; staff development; faculty development; teaching methods; higher education; staff adoption; engagement techniques

\section{Introduction}

The role of technology to enhance the delivery of teaching is one that is acknowledged to have the potential, where its use is well thought out, to transform the learning and teaching experience and support radical change (Keppell, Suddaby, and Hardy 2015). However, despite the affordances and opportunities that exist, as well as huge investments in technology that institutions have put in place to support this (Buabeng-Andoh 2012), barriers towards the adoption of technology are acknowledged throughout the literature. A lack of uniform understanding of key terms such as 'Technology Enhanced Learning' (TEL) (Kirkwood and Price 2014) can lead to differences in academic practice (Mirriahi, Alonzo, and Fox 2015). Therefore, it is important that TEL is unambiguously defined. Here, we adopt the U.K.' s Higher Education Academy (HEA) definition that describes TEL as 'a synonym for e-learning but can also be used to refer to technology enhanced classrooms and learning with technology, rather than just through technology e-learning' (HEA 2016). In this context, the term TEL should therefore be considered to encompass terms such as 'blended', 'digital', 'online', and 'distance learning'.

\section{*Corresponding author. Email: Farzana.Latif@sheffield.ac.uk}




\section{F. Latif}

This paper focuses on TELFest, a Technology Enhanced Learning Festival, which is an approach used at the University of Sheffield to encourage the adoption of educational technologies amongst teaching staff (i.e. academics). It investigates the impact of this approach, alongside barriers that are preventing changes from taking place, whilst further exploring ways in which such an approach can be improved. The paper begins by setting the scene and exploring the barriers to adoption, alongside different adoption strategies.

\section{Barriers to adoption}

Birch and Burnett (2009) carried out a literature review into the barriers related to the adoption of TEL and categorised the results into the following three themes: institutional, pedagogical and individual. These categories are further exemplified as follows:

- Institutional barriers can include a lack of institutional direction (Buchanan, Sainter, and Saunders 2013), and it is asserted that institutions should identify their own definitions and develop a clear vision of TEL in order to address the lack of common understanding. Lack of support may include limited access to suitable educational software and ICT equipment (Buabeng-Andoh 2012). Whilst not acknowledged by Birch and Burnett (2009), restrictions due to the curriculum (e.g. rigid structure) are also considered as part of this category; these restrictions may be a result of external factors such as collaborations with professional bodies (Ertmer and Ottenbreit-Leftwich 2010).

- Pedagogical barriers can include scepticism or the inability of teaching staff to see the value of technology within learning (Buabeng-Andoh 2012; Buchanan, Sainter, and Saunders 2013; Walker et al. 2016). Arguably, it can be difficult for teaching staff to contextualise the role of technology, as the individual's own learning experiences are likely to involve learning by 'traditional' teaching methods, and this will influence their own teaching methods (Reilly et al. 2012).

- Individual factors can include a perceived lack of time, resistance to change, lack of rewards and recognition, lack of skills and lack of confidence. Every 2 years, the Universities and Colleges Information Systems Association (UCISA) surveys UK institutions on their adoption of TEL and for the last six iterations (published between 2005 and 2016) 'time' has consistently been cited as the biggest barrier to TEL development (Walker et al. 2016). This is unsurprising considering the assertion of Vaughan (2007) in Alammary, Sheard, and Carbone (2014), who suggests that developing a blended course takes up to three times longer than if the equivalent course were to be delivered in a traditional format.

\section{Adoption strategies}

Rogers' (2003) diffusion of innovation theory describes the way in which cultures adopt an innovation, and it is a model commonly used when exploring the adoption of TEL (Wilson and Stacey 2004). Rogers categorises adopters as follows: (1) innovators, (2) early adopters, (3) early majority, (4) late majority and (5) laggards, where innovators are the first to adopt and laggards the last. Rogers explains, and other 
research has confirmed (Latif 2011), that innovators and early adopters can act as a positive force to promote and encourage adoption of technologies by the mainstream majority. However, Porter et al. (2016) draw on the work of Moore (2002) who warns that there is a 'chasm' between the early adopters and innovators and that the strategies used to engage these groups with an innovation will be different to the mainstream adopters. This outlines the importance of adopting different strategies to engage different groups of adopters (Robinson 2009). The work of Rogers has been contested as having little relevance to the adoption of learning technologies, with arguments suggesting that using this model encourages typecasting and that adoption can and should vary depending on the educational context and the relevance of the technology within that context (Eisenhauer and Keisch 2016).

Communities of Practice is a social learning theory based around the formation of usually informal, non-hierarchical, cross-institutional communities where members have shared learning needs (Lave and Wenger 1991). These communities develop over time; early stages involve members 'finding others' whilst more active communities can involve members working on joint activities and developing shared understandings (Wenger 1998). The value of communities of practice and the importance of the peer support that they can offer has been identified as a way of supporting the adoption of TEL within an institution (Austen et al. 2016; Nicolle and Lou 2008; Reilly et al. 2012). Early adopters and innovators can have a fundamental role to play in sharing their practice (Austen et al. 2016) and new expertise will grow from others within the community. However, to prevent a community from becoming too 'insular' in its practice, it is important to ensure that there is enough access to activity from 'outside' the communities' 'boundaries' to renew learning (Wenger 1998).

Formal staff development is a clear theme that acts as an enabling factor to the adoption of TEL, whether this is one-to-one, online, ad hoc workshops, or part of a structured programme (Alammary, Sheard, and Carbone 2014). The value of this is further supported by the 2016 EDUCAUSE Learning Initiative's 'Key Issues in Learning and Teaching' results, where 'faculty development', with a focus on enhancing the 'strengths and abilities' of teaching staff, was identified as one of the topics of most interest to universities (EDUCAUSE 2016). There is a strong consensus that it is important to focus on 'why to', (i.e. pedagogy and added value as part of staff development) and not just on 'how to' (Alammary, Sheard, and Carbone 2014; Johnson et al. 2012; Glover et al. 2012). In fact, some argue that it is more important to focus on the 'why', as this is where the real learning gain is with regards to developing a better understanding of TEL pedagogy (Johnson et al. 2012). On the other hand, it is being increasingly recognised that assumptions about the 'digital skills' possessed by both the teaching staff and students are frequently ill-founded (JISC 2015), further emphasising the importance of combining the 'why' with the 'how'. As well as this, it is considered important to develop teacher 'self-efficacy', that is, teacher confidence in using their skills and knowledge to facilitate student learning (Ertmer and Ottenbreit-Leftwich 2010).

Alammary, Sheard, and Carbone (2014) reviewed different blended learning approaches and proposed three distinct design approaches for the implementation of TEL; low impact (adding extra technology-enhanced activities to an existing course), medium impact (replacing existing activities in an existing course with technology-enhanced activities) and high impact (building a course from scratch). They argue that the higher the impact, the larger the potential change will be to a 


\section{F. Latif}

course and to the student learning experience. The model has been adopted as a method to encourage staff to think more deeply about their adoption of TEL (Learning Development Centre 2015), with the ultimate goal being that teaching staff will implement a high impact blend.

The importance of deploying different strategies to support the adoption of innovations is supported by a project to introduce a new virtual learning environment (VLE) integrated with other learning technologies at City University of London, where alternative methods were used depending on the culture and previous exposure to TEL within each of the schools of the university (Glover et al. 2012). Strategies employed included staff development (group workshops, one-to-one, online), student training, employing champions and the introduction of minimum standards for VLE-supported courses. The UCISA 2016 TEL survey's top three enabling approaches for the adoption and use of TEL tools across institutions are: (1) providing support and training to academic staff, (2) providing platforms for sharing good practice and (3) delivery of accredited programmes for academic staff (Walker et al. 2016). Some institutions have put in place a strategy of offering staff cash incentives, yet it has been argued that such initiatives offer no correlation with motivating teaching staff to adopt TEL (Johnson et al. 2012).

\section{Background to TELFest}

As described, it is important for institutions to integrate different strategies in order to encourage and support the adoption of TEL. TELFest is one approach that has been put in place to complement the current TEL support already available across the University of Sheffield, a research-intensive university in Northern England, which has approximately 3500 academic and learning and teaching support staff. This annual, week-long festival, introduced in September 2014, is organised by the institution's central Technology Enhanced Learning Team in collaboration with other teams that support TEL activity (e.g. library services) and is championed by the institution's Vice-President for Education, thereby offering institutional support at the highest level. The event was primarily aimed at staff involved in teaching students has also attracted academic support staff (e.g. librarians and TEL support staff such as learning technologists). Collectively, these attendees have the potential to form a community of practice consisting of those who wish to reflect on their own practice or support the practice of others. Prior to its inception, staff development opportunities related to TEL were seen as disjointed, and the festival offered an opportunity to showcase the type of support available across the institution and surface practice already taking place (e.g. from the early adopters and innovators), in order to support the wider scale adoption of TEL. The event is partly inspired by similar initiatives such as Blackboard festival, delivered by NUI Galway to create a sense of 'excitement and enthusiasm' around staff development (Flynn 2014).

A deliberately varied agenda allows staff to select the sessions that are of most interest to them, and unlike a conference, it is considered important that staff leave the event with the skills and actionable ideas that will allow them to change their practice immediately. In addition, sessions are devised to encourage staff to generate new ideas that could enhance their delivery of teaching and develop the confidence in expanding these. A variety of adoption strategies, such as those outlined in the previous section, have been employed to achieve this: 
- Show and tell sessions comprising of case studies of practice from teaching staff (e.g. early adopters and innovators) across the university, Mobile App Share, Innovation Corner (enabling attendees to consider how cutting edge research taking place within the institution could be valuable to learning).

- Panel discussions and debates, usually consisting of cross-faculty panels, to offer wide perspectives; examples of sessions that have run include: 'Opportunities and challenges with adopting TEL' and 'New opportunities for e-assessment'.

- Workshops (the majority of sessions fell into this category, exploring both 'how' and 'why'); these sessions were designed to offer a place to learn and make mistakes (to develop self-efficacy). These sessions varied from: more basic sessions (introduction to the VLE) through to emerging educational technology areas (e.g. Gamification) in teaching and learning. The sessions were often delivered by a member of the professional staff (e.g. educational developer, learning technologist) or co-delivered with a teaching colleague who is using a technology as part of their practice.

In order to develop the community of practice, networking opportunities are integrated within the agenda and a number of workshops encourage group activities, to further develop ideas and understanding of concepts collaboratively. Alongside this, one-to-one drop-in sessions run throughout the week, to support staff with specific questions or those who want to explore an idea further after they have attended a session. The sessions are delivered via a variety of different methods in order to model the practice being discussed. For instance, sessions on flipped learning and mobile learning use these same techniques to enable attendees to experience the method as students, supporting a situated method of learning (Lave and Wenger 1991). Attending TELFest is entirely voluntary and there is no formal accreditation linked to the sessions. However, digital badges are given to attendees to outline how participation at TELFest relates to the HEA's Professional Standards Framework for Teaching and Learning in Higher Education (HEA 2011).

\section{Approach/methodology}

At the time of carrying out this research, TELFest had run in September 2014, January 2015 and September 2016, and there had been a significant increase in the number of people that had attended, such that more than 400 staff within the institution have attended at least one of these festivals. The events now act as a core part of TELrelated staff development at the University of Sheffield. Whilst the events are attracting more people and receiving positive informal feedback, little is known about the impact of TELFest on the implementation of TEL at the university. Therefore, this investigation sought to answer the following questions: (1) What is the perceived impact of TELFest? (with an emphasis on changes to practice), (2) What are the ongoing barriers that are preventing changes to practice?, and (3) How could the long-term impact of TELFest be improved and sustained?

\section{Data collection}

To gain insight into these research questions, a web-based questionnaire was e-mailed to all staff that had previously attended TELFest, excluding those that had a key role 


\section{F. Latif}

in planning the festival (i.e. anyone involved in organising the entire event or involved in delivering more than one session). The questionnaire consisted of multiple choice and open-ended questions and was tested for reliability by other organisers of TELFest. Those that completed the form were asked whether they were willing to have their experiences explored further as part of a 45-60 min focus group. Ethical consent was obtained through the University of Sheffield's ethical review process.

\section{Data analysis}

In order to ensure integrity of the results, all data were anonymised, retaining only the role of the participant (e.g. teaching staff, support staff), and then aggregated before any analysis took place. The web-based platform used for the survey had its own analytical tools built-in and this was used to support the analysis of the quantitative portions of the responses. The open text responses, alongside transcription from the focus groups, were thematically analysed (Guest, MacQueen, and Namey 2011) in line with the research questions.

\section{Findings}

A total of 58 out of a possible 398 participants completed the initial questionnaire, a $14 \%$ response rate. Out of those that responded, 37(64\%) of respondents were teaching staff and $21(36 \%)$ were professional/administrative/support staff (principally learning technologists and academic developers). This split is typical of the demographic of TELFest attendees. Four focus groups were held, with between 2 and 5 participants in each, and in total there were 17 focus group participants.

\section{Perceived impact of TELFest}

(1) What is the perceived impact of TELFest? (with an emphasis on changes to practice)

\section{Changes to practice}

As part of the questionnaire, participants were asked to consider whether TELFest had helped them to generate new ideas, with a majority of participants $(40 ; 69 \%)$ agreeing with this. In total, 47 participants $(81 \%)$ said that they had already made or intended to make changes to their practice, and that these changes and plans were influenced by attending TELFest. A total of 31 participants (53\%) had made changes, whilst 16 participants $(28 \%)$ had planned but not yet implemented the changes. Respondents reported barriers that correlated to the barriers highlighted within the literature. These are outlined in subsequent findings.

Respondents who had made changes $(n=31)$ were further asked to specifically comment on the degree of impact of their changes, in line with the previously described impact model by Alammary, Sheard, and Carbone (2014). These questions were asked using a Likert scale. Cumulative responses alongside the mean and standard deviation for each of these sets of responses are provided in Table 1. Responses stating 'not applicable' and those with no response have been removed from this calculation. 
Table 1. Impact of changes $(n=31)$.

\begin{tabular}{|c|c|c|c|c|c|c|c|c|c|}
\hline \multirow[b]{2}{*}{ Questions } & \multirow[b]{2}{*}{ Indicative examples provided } & \multicolumn{2}{|c|}{$\begin{array}{l}\text { Strongly } \\
\text { disagree }\end{array}$} & \multirow[b]{2}{*}{3} & \multicolumn{2}{|c|}{$\begin{array}{c}\text { Strongly } \\
\text { agree }\end{array}$} & \multirow[b]{2}{*}{ Unanswered } & \multirow[b]{2}{*}{ Mean } & \multirow{2}{*}{$\begin{array}{l}\text { Standard } \\
\text { deviation }\end{array}$} \\
\hline & & 1 & 2 & & 4 & 5 & & & \\
\hline $\begin{array}{l}\text { Low impact: } \\
\text { Attending TELFest has } \\
\text { resulted in me [Adding } \\
\text { additional activities to a } \\
\text { module/course] }\end{array}$ & Enhancing design of VLE, Adding discussion boards & 0 & 1 & 2 & 20 & 5 & 2 & 4.03 & 0.64 \\
\hline $\begin{array}{l}\text { Medium impact: } \\
\text { Attending TELFest has } \\
\text { resulted in me [Changing } \\
\text { existing learning activities] }\end{array}$ & $\begin{array}{l}\text { Adding a Twitter back channel to large classroom } \\
\text { teaching; Introducing mobile learning activities to } \\
\text { replace traditional methods of teaching; } \\
\text { Incorporating game-based learning activities }\end{array}$ & 0 & 1 & 5 & 18 & 6 & 1 & 3.85 & 0.66 \\
\hline $\begin{array}{l}\text { High impact: } \\
\text { Attending TELFest has } \\
\text { resulted in me [Redesigning a } \\
\text { module or course] }\end{array}$ & $\begin{array}{l}\text { Redesign of face to face teaching; Move to a flipped } \\
\text { learning model of delivery; Redesign of assessment } \\
\text { activities }\end{array}$ & 3 & 3 & 11 & 7 & 3 & 4 & 3.14 & 1.13 \\
\hline
\end{tabular}




\section{F. Latif}

Examples of specific changes that have been made to practice are outlined in column 2 of this Table 1.

The results indicate that most changes made are in the low- and medium-impact range, with fewer reaching levels of high impact. The examples of changes provided were closely aligned to the sessions delivered throughout TELFest, and several respondents outlined multiple changes to practice, highlighting the importance of ensuring that sessions are relevant and resonate with participants. Developing low- and medium-impact activities offer opportunities to implement new technologies and develop confidence in them, whereas high-impact changes have more risk associated with them (Alammary, Sheard and Carbone 2014). All of those that had made changes indicated that they planned to make further changes, implying that they saw the integration of TEL as an ongoing process. Therefore, this could lead to higher impact change in the future as confidence increases. Additionally, those who are yet to make changes indicated that they plan to make changes when appropriate, highlighting that TELFest has made people think pedagogically rather than technologically about making changes: 'I haven't gone back and done things straight away. I've thought, "That's another tool for the toolbox.". When a good opportunity to use it comes along, then I will use it, rather than using it for the sake of using it'.

Respondents were further asked to consider how they planned to or how they have evaluated changes made to practice. Based on those that had made or intended to make changes, a minority (16 out of $47 ; 34 \%$ ) had considered this. Those who had considered ways to evaluate practice relied on standardised feedback (e.g. module/ course evaluation, although there was an acknowledgment that this might not necessarily surface feedback related to specific changes), changes to grades, direct informal feedback, no longer receiving bad feedback, analysing analytics related to online access of resources/completion of activities, and developing specific questionnaires for students to complete. One focus group participant said, 'I made changes to my course. It made me feel better, but I'm not sure if it offered value to my students'. This comment, alongside the minority that had considered ways to evaluate changes, suggests a lack of consideration towards evaluating practice, despite this being a key aspect of scholarly practice. However, lack of evaluation appears to be a sector-wide trend, as demonstrated by Kirkwood and Price (2013) in their literature review of TEL practices, which found that a scholarly approach to enhancing teaching and learning is seldom taken by teachers and policymakers. Additionally, at an institutional level, the 2016 UCISA TEL report (Walker et al. 2016) asked institutions whether they had 'evaluated the impact of technology enhanced learning tools and systems on the student learning experience across the institution' (Walker et al. 2016, p. 45) and found that less than half ( 40 of $99 ; 40 \%$ ) of the institutions that responded had done so within the last 2 years.

\section{Community of practice}

Responses indicated that the community of practice that has developed through TELFest has influenced changes to practice. In line with the diffusion of innovation theory, those already adopting a technology (e.g. early adopters and innovators) have played a key role in influencing these changes.

Learning from the experiences of innovators and earlier adopters has enabled attendees to generate new ideas and consider how similar technologies can be used 
within their own context. Respondents explained how understanding the successes and failures of others has further enabled them to identify what good practice looks like within their context, 'from TELFest we encounter the issues that others have had and have tried to ensure that we don't make the same mistakes'. This implies that delegates benefit from the experiences of peers in other disciplines, and this was reinforced by an academic describing how they had invited a speaker from another department to share practice at their departmental meeting. These examples are indicative of many others, where less experienced colleagues have drawn on the experience of innovators and early adopters to help to mainstream innovations.

There were also examples of long-term sustained relationships and activities beginning to form. An early adopter of flipped learning described being asked to peer review a session on flipped learning for another colleague after having presented at TELFest 'I had someone I met at TELFest contact me to peer review their use of flipped learning'. Others described how the community is developing through social media: '[I] sometimes correspond with people [I have connected with through TELFest] on twitter for ideas'. It was explained by one academic, how these relationships are important as they often work on their own when developing their modules/courses 'often you can feel quite isolated when teaching a module, you feel like an island, there are other islands that you can go to nearby, but you would have to get the boat out'. There was also evidence of new projects being formed with colleagues across disciplines, who they may not have otherwise met, 'new projects have formed as a direct result of attending'. As well as teaching and learning projects being formed, there was mention of a research project being identified, resulting in a cross disciplinary joint application.

Initially, TELFest was developed with the aim of creating a community of practice for academics. However, the combined community with both academic and support staff that arose has offered greater value. For academic staff, TELFest has enabled them to identify support staff, both at a departmental/faculty level and central level, who could help them to make changes to their practice after TELFest. Support staff outlined that the event gave them the opportunity to identify academic staff that were 'interested, just by their presence there', enabling them to connect with staff who might be willing to pilot new tools and techniques or share their practice with others. Support staff also talked about how they found TELFest a useful way to connect with other professional staff from different parts of the university and identified ways in which they could better work with each other to provide improved support to teaching staff, such as through collaborations across central teams (e.g. library and IT services) and between faculties.

\section{Ongoing barriers/challenges}

(2) What are the ongoing barriers that are preventing changes to practice?

Barriers reported by respondents aligned to Birch and Burnett's (2009) 'institutional' and 'individual' categories rather than those of a 'pedagogic' nature. This shows that the barriers are related more to external factors rather than a lack of knowledge, and are outlined below.

\section{Raising the profile of TEL (institutional barrier)}

There were strong views within the focus groups that the institution needed to do more to promote the importance of developing teaching as 'there has never been any proper 


\section{F. Latif}

value over teaching, not like there should be' and that this is reinforced through perceived limited promotion routes that exist for staff based on teaching, rather than research excellence.

However, feedback has indicated that TELFest has helped to raise the profile of TEL and the understanding of the breadth of activities that it encompasses 'the agenda offers a great overview of all the things I still need to learn'. Respondents were encouraged that the events are both supported and attended by staff at a senior level, highlighting the importance of senior buy-in for such initiatives. It was proposed that more still needed to be done to raise the understanding of TEL and that they would have liked to see more colleagues attending the event, with one delegate's explanation being 'I thought it was for IT managers, but next time I hope to go to more events' highlighting that there would be others that had this misconception. It was proposed in three of the focus groups that a better understanding of TEL and related staff development events such as TELFest could be achieved by creating clearer links within accredited routes (such as the HEA's UK Professional Framework and internally accredited programmes such as the postgraduate level certificate in learning and teaching).

\section{Departmental culture (institutional barrier)}

Several focus group attendees described how TELFest had inspired them and enabled them to generate new ideas, but when they returned to their department it was difficult to motivate change beyond their course - 'I wanted to get our department to mark online, colleagues did not like it, they said that they prefer paper'. In addition, some respondents felt that their colleagues were not invested in enhancing their teaching practice - 'it feels like my colleagues are behind the curve, things are almost stuck to where they were 30 years ago'. Such views imply that for some, teaching practice is a low priority and could provide insight as to why people don't engage with staff development events such as TELFest. There were further observations that there is not always enough encouragement to change practice at a departmental level and that when this encouragement did take place, it was as the result of bad feedback from students, and was therefore reactive rather than proactive change. However, it was clear that a lack of department support was not a view shared by all participants, and others spoke favourably about the support offered by the departments within which they work: 'I think that we have a very supportive environment', further showing that a single approach to staff development for the whole institution would likely be met with limited success.

\section{Individual barriers}

In line with the literature, 'lack of time' was the most cited reason to describe why changes had not yet been made. Participants explained how, having had time to contemplate their practice and possible alternatives, they walked away with ideas and new skills, but the ongoing pressures of their duties meant that once away from TELFest, they struggled to find the time to put in place the changes they wanted to make into place. This meant that people have not been able to find 'time to sit and focus on making the course as good as it could be' and in some cases has led to no changes being made, 'I had a couple of really good ideas but I haven't done anything'. 
Participants also described how other priorities, including research, administrative tasks, and other planned developmental work, prevented them from making the integration of TEL a priority. Suggestions to make time included blocking time out to make changes and having access to a list of support staff. One delegate proposed the idea of an organised 'TEL Retreat', lasting a period of 2-5 days, where participants could bring their ideas with them and develop their work with peers who also want to make changes and specialists, such as learning technologists, educational developers, and technology specialists. Such an event would help to further develop the community of practice by strengthening the support networks comprising of peers and support staff. On the other hand, there were also concerns as to whether, given the limitations to time and changes to technology, the invested time would be valuable: 'How long before I need to change what I do again?'

\section{Improving TELFest}

(3) How could the long-term impact of TELFest be improved and sustained?

The research has shown that whilst TELFest has resulted in significant change to practice, the potential long-term and ongoing impact can be increased in a number of ways and these are explored.

\section{Catering to an audience with a widening digital divide}

Whilst a significant proportion of TELFest attendees are returning participants, there has been an ever-increasing number of first-time attendees at each event. The importance of maintaining a balance between sessions for those new to TEL and those who have been making use of technology in their teaching for some time was recommended: 'there is a danger that it is just the same kind of topics each year, ... you need to keep it fresh if you want the same people to keep coming'. As was the need to appeal to new audiences '... you have an impossible job of catering for people that don't have a clue and others that are nuanced ... you need a mix of sessions'. It was also recommended that future sessions should clearly outline required prior knowledge and experience in order to support delegates in making informed choices when they select a session. Continuing to cater to a wide audience through delivering a wide variety of sessions will therefore continue to be essential when designing future TELFest agendas in order to ensure that colleagues regardless of their level of adoption are catered for. Furthermore, inviting external speakers could prevent the community from becoming too 'insular' (Wenger 1998).

\section{Timing}

TELFest is scheduled to run at the start of the academic semester, and this was specifically chosen to assist staff in developing their modules just before the start of the term. The majority of attendees indicated that the times the festivals run are appropriate and allowed them to make small changes and start to think about larger changes for the following semester, describing the festival as a 'good thing to come back to after the break'. Others expressed frustrations that there was not enough time to make significant changes, as in some cases teaching started the week after TELFest. Unfortunately, the nature of the institution and the varied programmes being taught 


\section{F. Latif}

means that the teaching cycle varies significantly and there is a clear consensus that there is no right time to arrange such events. As a result, there are plans to change the dates annually, in order to attract different audiences and provide staff with more time to make changes.

\section{Student digital literacy}

In all of the focus groups, the importance of supporting students and developing their skills was recognised. Concerns were also expressed that by not providing students with adequate support, they may use this as an excuse for not completing work 'my Internet is broken ...[has become synonymous with]... the dog ate my homework'. Respondents were also conscious of the importance of parity and equity '... [the institution is] Apple-centric ... [and I] don't want to exclude people'. It was proposed that TELFest could help raise awareness of the support that teaching staff should offer students when introducing a new TEL innovation.

\section{Ongoing support}

It was suggested that providing delegates with contact lists of those that support and are interested in developments in certain areas would assist in developing these relationships. A number of respondents highlighted that more opportunities to network and discuss ideas would be valuable during TELFest, as these relationships take time to develop. Developing events specifically for TELFest attendees after the event could also help to develop this community further.

\section{Ongoing promotion}

It was recommended that more should be done to promote the festivals at departmental meetings and by departmental learning and teaching leads, as there were still many people that were unaware of the event. If more people attended from a department, it was proposed that this would help to develop localised networks.

\section{Research limitations}

The research undertaken has helped to provide both a quantitative and qualitative insight into the research questions. However, from the small sample of participants, it is difficult to know whether the participants, who were self-selected, represent a sample of typical TELFest attendees. Excluded from participation were those that were heavily involved in shaping TELFest. In some cases, though, they attended the festival and may have been able to offer a different perspective. Additionally, widening the call for participation to those who had not previously attended could have provided more insight into ways that the long-term impact of TELFest could be improved. On the other hand, TELFest is aimed primarily at teaching staff, it also attracts wider audiences, so some of the questions asked were not applicable to all research participants. Differentiating teaching staff and support staff responses or asking each group different questions would have helped to better understand the different needs of each group. Furthermore, research related to the impact of TELFest 
could have been further strengthened by asking students about the perceived impact of the changes that teaching staff had made or planned to make.

\section{Conclusion}

This research has demonstrated that there have been positive benefits for those that have attended TELFest. These include generating new ideas, changing practice, developing support networks and forming collaborations. The majority of changes made to practice have been described as low and medium impact. However, there is an indication that high impact levels will be attained with time, as teaching staff become more confident and familiar with technology. Therefore there would be value in carrying out research in subsequent years to gauge whether the impact of change develops over time.

Since carrying out this research, a further TELFest ran in June 2016 and July 2017 (and will continue to run for the foreseeable future). These events saw an increase in the number of attendees, and in line with the findings, many changes have been put in place to ensure growth and long-term value. However, this research has highlighted barriers that exist at an institutional level; these issues are complex and lack uniformity. TELFest is just one of the methods used to support the academic adoption of TEL. The findings will feed into wider institutional initiatives that are taking place to address such issues and further support the adoption of TEL within the institution.

\section{Conflict of interest and funding}

No funding has been received for this study.

\section{References}

Alammary, A., Sheard, J. \& Carbone, A. (2014) 'Blended learning in higher education: Three different design approaches', Australasian Journal of Educational Technology, vol. 30 , no. 4 , pp. $440-454$.

Austen, L., Parkin, H., Jones-Devitt, S., McDonald, K., \& Irwin, B. (2016) Digital capability and teaching excellence: an integrative review exploring what infrastructure and strategies are necessary to support effective use of technology enabled learning (TEL). [online], Retrieved December 2, 2016, from http://www.qaa.ac.uk/en/Publications/Documents/ Digital-capability-and-teaching-excellence-2016.pdf

Birch, D. \& Burnett, B. (2009) 'Bringing academics on board: encouraging institution-wide diffusion of e-learning environments', Australasian Journal of Educational Technology, vol. 25, no. 1, pp. 117-134.

Buabeng-Andoh, C. (2012) 'Factors influencing teachers' adoption and integration of information and communication technology into teaching: A review of the literature', International Journal of Education and Development using Information and Communication Technology, vol. 8, no. 1, pp. 136-155.

Buchanan, T., Sainter, P. \& Saunders, G. (2013) 'Factors affecting faculty use of learning technologies: implications for models of technology adoption', Journal of Computing in Higher Education, vol. 25, no. 1, pp. 1-11.

EDUCAUSE. (2016) Key issues in teaching and learning, [online] Available at: http://www. educause.edu/eli/initiatives/key-issues-in-teaching-and-learning

Eisenhauer, Y. C. \& Keisch, D. K. (2016) Disrupting the technology adoption spectrum: thinking creatively about faculty technology use, [online] Available at: http://www.educause.edu/ events/ELI16/SESS25

Ertmer, P. A. \& Ottenbreit-Leftwich, A. T. (2010) 'Teacher technology change: how knowledge, confidence, beliefs, and culture intersect', Journal of research on Technology in Education, vol. 42, no. 3, pp. 255-284. 


\section{F. Latif}

Flynn, S. (2014) The blackboard festival, [online] Available at: https://prezi.com/vbfrmtljfaqu/ the-blackboard-festival/

Glover, I., et al., (2012) 'A tale of one city: intra-institutional variations in migrating VLE platform', Research in Learning Technology, vol. 20.

Guest, G., MacQueen, K.M. \& Namey, E.E. (2011) Applied thematic analysis, Sage, CA, USA.

HEA. (2011) The UK professional standards framework for teaching and supporting learning in higher education, [online] Available at: https://www.heacademy.ac.uk/sites/default/files/ downloads/ukpsf_2011_english.pdf

HEA. (2016) Technology enhanced learning (TEL) toolkit | Higher Education Academy, [online] Available at: https://www.heacademy.ac.uk/enhancement/toolkits/technology-enhancedlearning-tel-toolkit

JISC. (2015) Developing digital literacies, [online] Available at: https://www.jisc.ac.uk/guides/ developing-digital-literacies

Johnson, T., et al., (2012) 'Technology adoption in higher education: overcoming anxiety through faculty bootcamp', Journal of Asynchronous Learning Networks, vol. 16, no. 2, pp. 63-72.

Keppell, M., Suddaby, G. \& Hard, N. (2015) 'Assuring best practice in technology-enhanced learning environments', Research in Learning Technology, vol. 23.

Kirkwood, A. \& Price, L. (2013) 'Missing: evidence of a scholarly approach to teaching and learning with technology in higher education', Teaching in Higher Education, vol. 18, no. 3 , pp. $327-337$.

Kirkwood, A. \& Price, L. (2014) 'Technology-enhanced learning and teaching in higher education: what is 'enhanced' and how do we know? A critical literature review', Learning, Media and Technology, vol. 39, no. 1, pp. 6-36.

Latif, F. (2011) Designing, planning and implementing learning technologies through engaging teachers, [online] Available at: http://archive.alt.ac.uk/conference/altc2011.alt.ac.uk/talks/ 22233.html

Lave, J. \& Wenger, E. (1991) Situated learning: Legitimate peripheral participation, Cambridge University Press, CA, USA.

Learning Development Centre. (2015) The blended learning design framework, [online] Available at: https://sleguidance.atlassian.net/wiki/display/BL/The+blended+learning+design+framework

Mirriahi, N., Alonzo, D. \& Fox, B. (2015) 'A blended learning framework for curriculum design and professional development', Research in Learning Technology, vol. 23.

Moore, G. A. (2002) Crossing the chasm: Marketing and selling disruptive products to mainstream customers, HarperCollins, NY.

Nicolle, Pam, S. \& Yiping, Lou (2008) Technology adoption into teaching and learning by mainstream university faculty: A mixed methodology study revealing the "How, when, why, and why not", Journal of Educational Computing Research, vol. 39, no. 3, pp. 235-265.

Porter, W.W., Graham, C.R., Bodily, R.G. \& Sandberg, D.S. (2016) 'A qualitative analysis of institutional drivers and barriers to blended learning adoption in higher education', The Internet and Higher Education, vol. 28, pp. 17-27.

Reilly, J.R., Vandenhouten, C., Gallagher-Lepak, S. \& Ralston-Berg, P. (2012) 'Faculty development for e-learning: a multi-campus community of practice (COP) approach', Journal of Asynchronous Learning Networks, vol. 16, no. 2, pp. 99-110.

Robinson, L. (2009) Changeology, [online] Available at: http://www.enablingchange.com.au/ Summary_Diffusion_Theory.pdf

Rogers, E. M. (2003) Diffusion of innovations, 5th edn, Free Press, NY, CA, USA.

Williams, S. (2014) 'Embedding technology enhanced learning at universities: a collaboration between University of Cumbria and Newcastle University', Journal of Learning Development in Higher Education.

Vaughan, N. (2007) Perspectives on blended learning in higher education, International Journal on ELearning (IJEL), vol. 6, no. 81, pp. 81-94.

Walker, R., et al., (2016) Survey of technology enhanced learning for higher education in the UK, Universities and Colleges Information Systems Association, Oxford.

Wenger, E. (1998) Communities of practice, Cambridge University Press, CA, USA.

Wilson, G. \& Stacey, E. (2004) 'Online interaction impacts on learning: teaching the teachers to teach online', Australasian Journal of Educational Technology, vol. 20, no. 1, pp. 33-48. 